\title{
WAGENINGEN
}

UNIVERSITY \& RESEARCH

\section{A systematic review of local vulnerability to climate change in developing} country agriculture: In search of transparency, coherence and comparability

\author{
Crane, T. A., Delaney, A., Tamás, P. A., Chesterman, S., \& Ericksen, P.
}

This article is made publically available in the institutional repository of Wageningen University and Research, under article 25fa of the Dutch Copyright Act, also known as the Amendment Taverne.

Article $25 \mathrm{fa}$ states that the author of a short scientific work funded either wholly or partially by Dutch public funds is entitled to make that work publicly available for no consideration following a reasonable period of time after the work was first published, provided that clear reference is made to the source of the first publication of the work.

For questions regarding the public availability of this article, please contact openscience.library@wur.nl.

Please cite this publication as follows:

Crane, T. A., Delaney, A., Tamás, P. A., Chesterman, S., \& Ericksen, P. (2017). A systematic review of local vulnerability to climate change in developing country agriculture: In search of transparency, coherence and comparability. Wiley Interdisciplinary Reviews: Climate Change, 8(4), [e464]. https://doi.org/10.1002/wcc.464 


\section{A systematic review of local vulnerability to climate change in developing country agriculture}

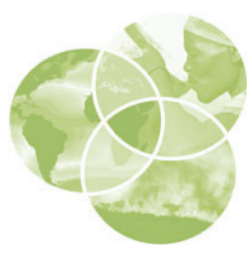

Todd A. Crane, ${ }^{1 *}$ Aogán Delaney, ${ }^{2}$ Peter A. Tamás, ${ }^{2}$ Sabrina Chesterman ${ }^{3,4}$ and Polly Ericksen ${ }^{1}$

Edited by Maria Carmen Lemos, Domain Editor, and Mike Hulme, Editor-in-Chief

In the mid-2000s, several highly-cited papers called for improving conceptual coherence and methodological transparency in vulnerability research to support greater policy relevance. As reducing vulnerability rises on political agendas, identifying empirically validated measures will become increasingly important in the design and evaluation of multi-site and multi-scale programmatic interventions. Using a systematic review methodology, we analyze the current range of conceptual frameworks, operationalizations and research methodologies as used in empirical studies of local-level vulnerability in agricultural settings. Detailed analysis of theories and methods provides a platform for moving toward reporting that supports valid comparisons between disparate studies. This in turn, enables the design and implementation of empirically-informed programmatic interventions. The results show that earlier concerns remain relevant. Even the best reported cases do not support aggregated analysis because conceptual ambiguity and methodological heterogeneity renders each study effectively unique. While conceptualization is broadly consolidating around the IPCC framework, declaration of that framework does not predict consistent operationalization. Furthermore, emerging alternative frameworks, especially Vulnerability as Expected Poverty, reveal important limitations of the IPCC framework. Findings also highlight that reporting practices in vulnerability research perpetuate problematic ambiguity. When designing and reporting research, we recommend addressing six key questions that can help specify the objectives of the study: (1) Is this system vulnerable? (2) To what is this system vulnerable? (3) How vulnerable is this system? (4)What is causing this system to be vulnerable? (5) How is vulnerability distributed within the system? (6) What is causing the observed distribution of vulnerability within the system? @ 2017 Wiley Periodicals, Inc.

How to cite this article:

WIREs Clim Change 2017, 8:e464. doi: 10.1002/wcc.464

Additional Supporting Information may be found in the online version of this article.

*Correspondence to: t.crane@cgiar.org

${ }^{1}$ Sustainable Livestock Systems, International Livestock Research Institute, Kenya

${ }^{2}$ Research Methodology Group, Wageningen University, Netherlands

\footnotetext{
${ }^{3}$ World Agroforestry Centre, International Agroforestry Research Center, Kenya

${ }^{4}$ London School of Hygiene and Tropical Medicine, London, UK Conflict of interest: The authors have declared no conflicts of interest for this article.
} 
There does not exist a category of science to which one can give the name applied science. There are sciences and the applications of science, bound together as the fruit of the tree which bears it. Louis Pasteur, Revue Scientifique (1871)

\section{INTRODUCTION}

C oinciding with numerous international agreements around climate change and development, ${ }^{1}$ the mid-2000s saw a suite of publications calling for greater conceptual and methodological consolidation within the field of climate vulnerability research. These heavily cited publications took several different forms, including reviewing the evolution of vulnerability research approaches, ${ }^{2-4}$ reviewing the conceptual connections between vulnerability and adaptation, ${ }^{1,5-7}$ proposing integrative frameworks for vulnerability research ${ }^{4-6,8-10}$ and outlining key issues and challenges for the field of vulnerability research. ${ }^{2,8,10}$ These conversations have continued with more recent publications. ${ }^{11-15}$

In addition to conceptual consolidation, many publications also call for improvements in the methodological coherence and standards of evidence. In order to progress, the field requires 'robust and credible measures' (Ref 2, p. 268). Furthermore, greater attention to clarity in reporting the specific parameters of vulnerability assessments is needed because such clarity 'inhibits overly ambitious research claims and facilitates meta-analyses and cross-case study comparisons' (Ref 3, p. 385-387). Similar positions advocating more robust methodologies and greater clarity in reporting objectives, methods and measures can be found in other publications. ${ }^{2,10,16}$

The overarching message from the mid 2000s was that vulnerability research needed far greater conceptual and methodological coherence in order to create a body of work that could meaningfully inform policies, programmatic interventions for vulnerability reduction and scientific synthesis. Within this context, one important contribution that research can make is clarifying what exactly adaptive capacity is, identifying its drivers and processes by which it can be enhanced, and providing tools for tracking changes in it. One way for research to strengthen any such contributions is to test research tools in multiple settings and compare results so that the scientific inputs to policy making are well founded. This requires careful examination of and reflection upon choices made in development of research tools and how the results may be compared.
Though it is often difficult to account for policy makers' degree of receptiveness to scientific evidence and argumentation, lack of coherence within vulnerability research approaches has significant implications for any programmatic efforts that require comparability. For example, the Indian State Action Plan on Climate Change aimed to create a synthetic overview of vulnerability in the country, but individual states conducted their underlying analyses using different frameworks, methodologies and measures. The incompatibility of the disparate studies ultimately undermined the synthesis required for coherent and wellinformed policy interventions at the national level. ${ }^{17}$ More recently, following on the 2015 Conference of Parties (COP15) in Paris, calls have emerged for more robust and valid measures of adaptive capacity, a key leg of the IPCC's vulnerability framework. ${ }^{18}$

Since the mid-2000s, there has been a wealth of empirical research on vulnerability to climate change, particularly in relation to smallholder agricultural systems, which are the focus of this paper (henceforth 'vulnerability'). Combined with the programmatic and political demands for valid indicators, this has led to the question of whether there has been sufficient progress toward coherence to support scientifically valid and generalizable measures of vulnerability. In essence, the objectives of this review are to test the degree to which the field has responded to critiques from the mid 2000s, to evaluate strengths and weaknesses of current practices in the field and to create a rigorous and empiricallyinformed platform for deliberation of future directions.

The research presented in this paper was commissioned by the Climate Change, Agriculture and Food Security (CCAFS) program. The initial mandate was to identify scientifically validated measures of local-level vulnerability in agricultural production systems. The idea was that results would be instrumental in the planning of vulnerability reduction activities across diverse production systems, as well as the monitoring and evaluation of those activities. This mandate was pursued through a systematic review of the most recent empirical studies within the particular domain of local agricultural vulnerability in developing countries. However, preliminary efforts quickly encountered insurmountable problems with lack of cross-case comparability. This led to retooling the project to describe and analyze the range of theoretical, conceptual and methodological choices made within recent, empirical vulnerability studies.

Through dissecting researchers' choices made in the formulation of frameworks, constructs, operationalizations and methodologies of vulnerability 
studies, this review provides a transparent and empirically-informed foundation for improving validity and comparability of vulnerability research. Due to aforementioned shortcomings in comparability and our adherence to methodological transparency of systematic review, we do not presume to make conclusive evaluation about the robustness of particular frameworks, concepts or methods: the available evidence is simply inadequate to support such conclusions. Instead, we seek to lay out our findings before the community of vulnerability researchers in order to inform discussion about whether, how and when to improve coherence and comparability of research within the domain. Strengths and weaknesses of various approaches are identified and recommendations are given regarding paths forward for the next decade of vulnerability research.

\section{Measuring Vulnerability}

Vulnerability is notoriously difficult to measure because assessments must assume theoreticallyspecified relationships between often non-observable elements. These elements are hypothesized to constitute vulnerability within theoretically informed models that are then measured through sets of diverse proxy indicators. ${ }^{12,19,20}$ The measurement of vulnerability is further complicated by the fact that it emerges through complex interactions between biophysical and social dimensions across multiple scales, all of which vary across time, location, the nature of biophysical stressors and outcomes of interest. ${ }^{10}$ Furthermore, specific measures must then be interpreted and aggregated into indicators and indices. Critical analysis of methods for aggregation are beyond the scope of this paper. As such, we deliberately focus on 'measures' rather than 'indicators' throughout the paper. When it comes to validating measures, we start with the common scientific assumption that measures' robustness and credibility are established through repeated application and testing in a wide variety of case studies. When adequately reported, this enables valid cross-case comparison, which in turn supports both stronger theorization of vulnerability as well as practical recommendations.

We use systematic review to examine a carefully selected sample of local-level case studies explicitly examining causal drivers of vulnerability. Our screening strategy selected for publications that are well-reported according to a variety of established criteria, ${ }^{21}$ including clear presentation of a research question, descriptions of sampling process, data collection methods, and data analysis. Furthermore, our screening strategy selected publications that go beyond simple description to analyze and draw conclusions on causal determinants of vulnerability. This selection strategy is justified by the goal of producing programmatically relevant guidance for the design and evaluation of interventions. Such programmatic interests would benefit most from commensuration of research through allowing multi-site aggregation and comparison that would enable robust measures across multiple regions and production systems.

Following on other reviews of theoretical, analytical and measurement approaches in adaptation research, we intend for this careful analysis of vulnerability studies to '... serve as a starting point for a more rigorous basis for the coherent exchange of methodological arguments in the field' (Ref 22, p. 172).

\section{Systematic Review}

Systematic review is a formal research methodology developed to identify, assess, and interpret available evidence on a chosen topic and specific research question. ${ }^{23}$ The methodology originated in early $1990 \mathrm{~s}$ health sciences, when scholars developed the method for systematically analyzing data from multiple Randomized Controlled Trials (RCT) in healthcare interventions. ${ }^{24,25}$ Systematic review's transparency, rigor, and replicability have led it to become a research method in own right, in contrast to traditional literature reviews. ${ }^{25}$ Systematic review typically consists of the following steps: search; selection of studies to be included in the review; extraction of data from subject literature; and the secondary analysis of extracted data. ${ }^{25,26}$ Each of these steps is pursued through a method that embodies the principles of rigor, transparency, reliability, and comprehensiveness.

Systematic review has increasingly been adapted to a broader range of fields, including research topics in the domain of climate change such as adaptation actions, ${ }^{27}$ links to food security, ${ }^{28}$ use of climate information in long-term policy planning, ${ }^{29}$ and the use of case study and climate analogue methodologies. ${ }^{30}$ In addition to covering new fields, systematic review has also been adapted to provide comprehensive description and rigorous appraisal of methods rather than data, with the aim of generating more robust constructs, operationalizations, or measures. ${ }^{31-34}$

This paper takes a different approach than the many review papers on the conceptualization of vulnerability. While some recent work has used systematic review to examine the range of conceptual elements in climate change vulnerability research, ${ }^{15}$ and others have carefully examined analysis methods, ${ }^{22}$ we take the extra and unique step of 
studying entire operationalizations, using conceptual deconstruction to link the various theories, constructs and methods of data collection and analysis. Additionally, rather than accepting frameworks as stated by authors, we analyze the construction of vulnerability in research practice through a bottom-up systematic review methodology of 'construct-centered methods aggregation, ${ }^{34}$ designed to dissect the use of constructs, operationalizations and methodologies within the papers. This permits critical examination of construct definitions and harmonizes authors' use of constructs. It also permits interrogation of the theoretical frameworks authors report having used through analysis of how they are operationalized. In adopting this inductive approach, our review enables theoretically contextualized study of vulnerability measures and it corrects for the authors' highly variable use of 'general labels' (Ref 22, p. 172).

\section{METHODS}

This section has been distilled from a working paper $^{35}$ and an exhaustive technical report, ${ }^{36}$ which readers can refer to for more detailed information about the steps presented here. Our review was guided by four research questions:

- How is vulnerability conceptualized?

- How is vulnerability operationalized?

- Which operationalizations are empirically valid?

- Which conceptualizations are supported by sound operationalizations?

\section{Selection of Literature}

An initial pool of articles was identified through a keyword search carried out across 15 scientific databases (see Appendices S1-S3, respectively (Supporting Information) for databases, search terms and a PRISMA diagram ${ }^{37}$ of the systematic review process). This search returned 168 papers. Initial title-abstract screening for relevance reduced the pool of articles to 71 . Each of these 71 articles was then subject to a full text screening for relevance and face interpretability (see Table 1). The condition 'face interpretability,' operationalized as the question 'is this article readily interpretable?' was met when the text clearly linked theory, operationalizations and measures for at least one construct used in the primary research question. Screening criteria were developed based on the Critical Appraisal Skills Program appraisal checklists, which are designed to facilitate quality appraisals of published research. ${ }^{21}$

Thirty-one papers met these inclusion criteria and were brought forward. Preliminary inspection of these 31 articles showed that authors did not use terminologies consistently, leading to concerns that the keyword searches used in the initial selection of literature might not have produced a valid sample. To address this uncertainty, we conducted a round of expert solicitation. ${ }^{38}$ To structure experts' suggestions of new articles, the team prepared a summary of the theoretical frameworks found in the selected papers. Articles were categorized by theoretical framework using the constant comparative method. ${ }^{39}$ From each category the best documented article was identified as an exemplar. These summaries and exemplars were sent to 31 topical experts-chosen on their publication records-who were asked to criticize our categorization and to nominate alternative exemplars. Expert solicitation produced eight new suggested articles which were then screened for relevance. Seven of these were brought forward, resulting in a final pool of 38 articles to be fully analyzed (see Appendix S4).

\section{Identification of Frameworks, Constructs and Operationalizations}

The first step of analysis was to code articles for elements of theoretical frameworks and their operationalizations. All coding was done according to a specified protocol, which was blind pre-tested for inter-coder reliability to minimize the influence of individual reviewers' subjectivity (Ref 36, p. 12-14). We used an idealized structure of a theoretical framework following ${ }^{40,41}$ which is illustrated in Figure 1, with key terms defined in Table 2.

We coded theoretical frameworks deductively. Because authors' use of terms was inconsistent, we could not use author-identified constructs as a basis for identifying theoretical frameworks. For example, authors who claimed to have used the IPCC framework, often did not use the same constructs. Consequently, we used four a priori identified frameworks and a miscellaneous category to initially classify articles according to their author-identified theoretical frameworks.

Constructs, definitions, relationships, and operationalizations used in the articles' research questions were coded inductively. Relationships between constructs were coded for use in synthesizing sibling constructs to produce their shared parent constructs. For example, labor, livestock and a few other things, once combined, may become 'household assets,' which in turn is one of several sibling constructs that 
TABLE 1 | Relevance and Quality Criteria Used in Full-Text Screening

\begin{tabular}{|c|c|}
\hline Criteria & Rationale \\
\hline Located in the global tropics & $\begin{array}{l}\text { Focuses review on studies and measures likely to be of relevance } \\
\text { to priority sites of interventions and outcome monitoring. This } \\
\text { review was funded by CCAFS, which has a mandate to focus } \\
\text { on developing countries. }\end{array}$ \\
\hline Local-level focus of assessment & $\begin{array}{l}\text { Most vulnerability studies for smallholder agriculture focus here, } \\
\text { and also it is most relevant for designing interventions aimed } \\
\text { at vulnerability reduction. }\end{array}$ \\
\hline Clearly stated research question & $\begin{array}{l}\text { Full reporting is necessary to assess quality of operationalizations. } \\
\text { We wished to exclude as much as possible those studies which } \\
\text { are insufficiently transparent to allow a quality appraisal. }\end{array}$ \\
\hline $\begin{array}{l}\text { Clearly described sampling process and data collection methods; } \\
\text { methodology that used empirical data (primary or secondary, } \\
\text { qualitative or quantitative) }\end{array}$ & $\begin{array}{l}\text { Full reporting is necessary to assess quality of operationalizations. } \\
\text { We wished to exclude as much as possible those studies which } \\
\text { are insufficiently transparent to allow a quality appraisal. }\end{array}$ \\
\hline Description of data analysis & $\begin{array}{l}\text { Full reporting is necessary to assess quality of operationalizations. } \\
\text { We wished to exclude as much as possible those studies which } \\
\text { are insufficiently transparent to allow a quality appraisal. }\end{array}$ \\
\hline $\begin{array}{l}\text { Analysis section went beyond simple description of determinants } \\
\text { and attempted to unpack the causality of vulnerability }\end{array}$ & $\begin{array}{l}\text { Much vulnerability research is descriptive. The interest of the } \\
\text { review is in research frameworks that examine drivers of } \\
\text { vulnerability. }\end{array}$ \\
\hline $\begin{array}{l}\text { Findings and analysis were focused on vulnerability outcomes and } \\
\text { determinants specifically (rather than topical areas such as } \\
\text { adaptive capacity, resilience or coping mechanisms) }\end{array}$ & $\begin{array}{l}\text { Much research focuses on topics which are immediately related } \\
\text { to, or components of, vulnerability. This criteria narrows } \\
\text { selection that only deal with vulnerability in entirety. }\end{array}$ \\
\hline Draws conclusions about vulnerability determinants & $\begin{array}{l}\text { The interest of the review is in research frameworks that examine } \\
\text { drivers of vulnerability. Frameworks used in studies which do } \\
\text { not draw conclusions about determinants of vulnerability are } \\
\text { unlikely to be of relevance to the purposes of the review. }\end{array}$ \\
\hline
\end{tabular}

combine to form 'adaptive capacity.' Constructs were excluded if they were neither defined nor operationalized. In total, we identified 395 author-specified

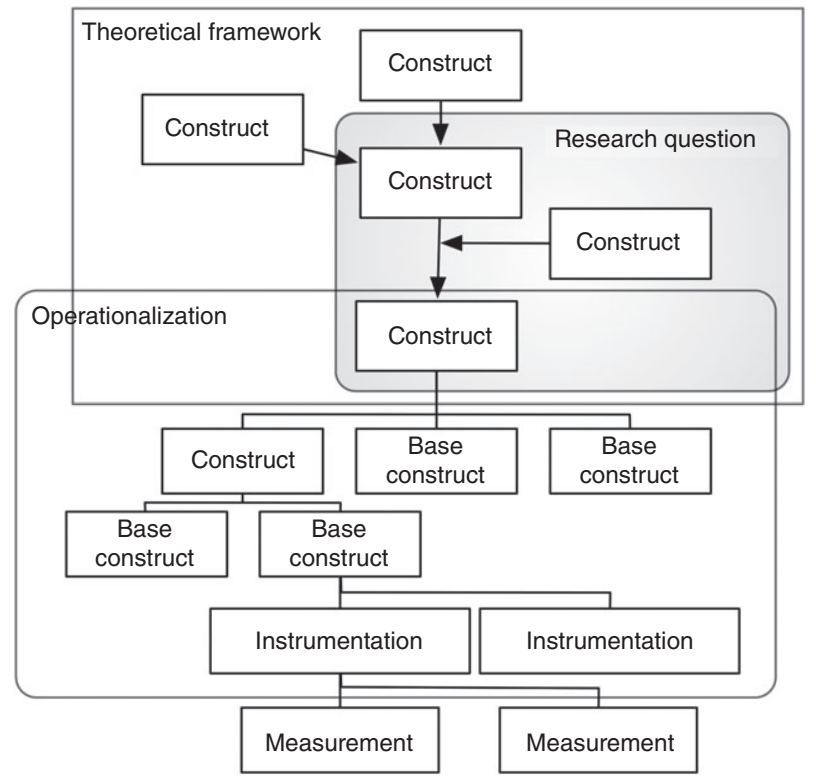

FIGURE 1 | Idealized theoretical framework. constructs, of which 299 were defined directly or through citation and of which 158 were directly operationalized.

\section{Synthesis of Frameworks and Constructs}

We recursively synthesized constructs, definitions, and relationships to inductively produce the theoretical frameworks actually used by authors. These inductively identified frameworks were used to correct for authors' inconsistent use of terms. Within each of the clusters of articles identified at the outset, the inductively identified frameworks were compared, using cultural domain anal$\mathrm{ysis}^{42}$ to test whether they were, in fact, the same. Where articles in a cluster were found to be mutually distinct, they were split into separate categories. Once all clusters were examined and appropriate categories formed, one exemplar article was selected from each category and compared to those from other categories in order to assess whether those categories were distinct. After merging through inductive analysis and then evaluation by the team's subject matter expert (SME), our initial set of 27 posited theoretical frameworks was reduced to 17 actual frameworks. 
TABLE 2 | Definition of Key Terms

\begin{tabular}{|c|c|}
\hline Key Terms & Definitions \\
\hline Theoretical framework & $\begin{array}{l}\text { A theoretical framework is composed of constructs, construct definitions, and relationships. The } \\
\text { theoretical framework provides the terms within which research is conceived, undertaken and } \\
\text { interpreted. }\end{array}$ \\
\hline Construct & $\begin{array}{l}\text { An object or idea as found in a theoretical framework. For example, the IPCC framework uses the } \\
\text { construct 'vulnerability.' }\end{array}$ \\
\hline Construct definition & $\begin{array}{l}\text { A statement that conceptually gives a construct meaning. This definition describes characteristics or } \\
\text { functions that determine what the concept is and/or by contrast to other constructs what it is not. }\end{array}$ \\
\hline Construct relationships & $\begin{array}{l}\text { Functional or taxonomic relationships between constructs. Constitutes the internal structure of a } \\
\text { theoretical framework. At times overlaps with construct definition. }\end{array}$ \\
\hline Child-constructs & $\begin{array}{l}\text { A construct taxonomically subordinate to its parent. For example, in the IPCC framework 'exposure,' } \\
\text { 'sensitivity,' and 'adaptive capacity' are subordinate to, and taken together form, 'vulnerability.' }\end{array}$ \\
\hline Parent-construct & $\begin{array}{l}\text { A construct produced by merging child-constructs. For example, in the IPCC framework } \\
\text { 'vulnerability' is the combination of 'exposure,' 'sensitivity,' and 'adaptive capacity.' }\end{array}$ \\
\hline Base-construct & $\begin{array}{l}\text { A construct for which no child constructs exists and which should ideally be directly measured. For } \\
\text { example, 'temperature' (measured in }{ }^{\circ} \mathrm{C} \text { ) may be one of several children of 'exposure.' }\end{array}$ \\
\hline Top construct & $\begin{array}{l}\text { The highest level construct found in the theoretical framework that is formed through recursive } \\
\text { combination of child-constructs. For example, 'vulnerability.' }\end{array}$ \\
\hline Sibling construct & $\begin{array}{l}\text { Constructs that are linked to each other by having a common parent. For example, 'exposure' and } \\
\text { 'sensitivity' are siblings as they are both components of 'vulnerability.' }\end{array}$ \\
\hline Operationalization & $\begin{array}{l}\text { Any act decomposing constructs to the point that they become measurable including both the } \\
\text { intermediate steps of conceptual decomposition into sub-constructs, as well as the final step of } \\
\text { specifying practices for measurement. }\end{array}$ \\
\hline $\begin{array}{l}\text { Author identified (construct/ } \\
\text { framework) }\end{array}$ & The term used by an author to denote a construct or a framework. \\
\hline $\begin{array}{l}\text { Inductively identified } \\
\text { (construct/framework) }\end{array}$ & The term generated through analysis in this study to denote a construct or framework. \\
\hline Instrumentation & Design of data collection and analysis strategies to substantiate constructs \\
\hline Measurement & Collection of empirical data \\
\hline
\end{tabular}

After inductively describing frameworks, we then identified key constructs within each framework. Owing to inconsistent use of terms, we could not rely on the authors' terms to conclusively identify common constructs. We, therefore, tentatively clustered constructs by the terms used (e.g., household assets) and then examined the definitions of identically named constructs to assess equivalence. Most of the constructs we encountered appeared in only one article $(n=123)$ and were, thus, uniform by default. Fourteen adequately defined constructs were found in more than one article. Of these, 10 identically named constructs were found to be similarly defined across articles and were judged to be uniform. Four identically named constructs had dissimilar definitions across articles and were split. We then compared definitions used for non-identically named constructs. We found 27 instances where differently named constructs were equivalent. For an extreme example, constructs with such diverse labels as 'adaptation to long-term climate change ${ }^{43}$ and 'farmer perceptions, ${ }^{44}$ were both found to be effectively referring to farmers' subjective evaluations of how climate had changed and were thus merged as 'farmer perceptions.' From the original 27 constructs, eight inductively identified constructs were created. In order to counteract the subjectivity of decisions made by individual reviewers, the team's SME then reviewed the work to validate or refute the decisions made (splitting, joining and/or renaming constructs and frameworks; screening out of non relevant frameworks).

\section{Transparency Assessment of Operationalized Constructs}

An instrument adapted from Da Silva ${ }^{45}$ was used to test operationalization of constructs for transparency, which is required for interpretation, replication and comparison of studies. This assessment used a specified and pre-tested protocol (Ref 36, p. 27-34) to minimize reviewer bias and recognizes an operationalization as transparent when it is possible to identify a corresponding definition, data collection methods, and data analysis methods. The criteria for this 
assessment were selected to determine the presence of information required to test validity. We conducted the transparency test on 151 base constructs and found, 117 to be transparent. Transparently operationalized base constructs were brought forward to evaluate their adequacy and feasibility.

\section{Assessing if Operationalizations are Adequate and Feasible}

Because quality and feasibility assessment requires subject matter competence, this stage of analysis was carried out solely by the team member with the most knowledge of the vulnerability field (the SME). Guided by systematic principles ${ }^{46}$ and with checks against subjective reviewer bias (Ref 36, p. 27-34), the SME evaluated whether

- The data collection methods adequately represent the construct as defined,

- The data collection and analysis methods and provide a complete valid understanding of the construct defined,

- Operationalization of each construct is programmatically feasible.

Operationalizations that were found to be coherent, valid and practicable were identified as candidates for inclusion in an inductively specified theoretical framework.

\section{Integration of Candidate Operationalizations into Inductively Specified Frameworks}

All base constructs found to be valid and feasible were then linked to top constructs in research questions. Inductively identified constructs in inductively identified frameworks were matched to article-specific base constructs using 'operational chains.' Operational chains are the relationships that specify which and how child constructs are combined into a parent construct. Where more than one viable operationalization was found for a top construct, all options were brought forward with contextual information that would help a SME to make an informed selection.

\section{RESULTS}

\section{Summary of Frameworks Identified in Review}

We first describe the theoretical frameworks that have been found and used to study vulnerability. A theoretical framework is composed of constructs and relations between these constructs. Of the 38 articles surveyed, 17 frameworks were found, with 12 frameworks seen as within the scope of the review, with the remaining five frameworks ${ }^{47-51}$ being excluded from further examination. Relevant constructs from excluded frameworks were retained for analysis. The analysis found three fully-defined relevant frameworks: IPCC with variants, Patterns of Smallholder Vulnerability and Vulnerability as Expected Poverty with extensions. In this context, 'fully-defined' means definitions could be found in the documents reviewed for all core constructs in the framework.

Beyond these most prevalent frameworks, there were four others that were not analyzed because there was not sufficient data (publications) in our review for us to systematically create coherent representations of them through the repeated use of their core constructs. These included Resilience and Vulnerability, ${ }^{52}$ Current and Future Vulnerability, ${ }^{53}$ Livelihood Vulnerability Index, ${ }^{54}$ and Nested Vulnerability. ${ }^{55}$ It is important to note that our choice not to analyze the framework is informed by the lack of prevalence in the sample, not by the specificity of reporting. It is a result of our efforts to be systematic, and not a reflection on the quality of the underlying studies.

Another group of frameworks were those found to have insufficient definition of constructs to permit adequate analysis. In this category, six frameworks emerged: Asset Vulnerability ${ }^{56}$ Intensifying Vulnerability to Food Insecurity ${ }^{57}$; Livelihood Trajectories, ${ }^{58}$ Household Vulnerability Factors ${ }^{59}$; Perceptions of Climate Change. ${ }^{43,44,60,61}$ In this group of frameworks most of the core constructs were not explicitly operationalized within the article(s) reviewed, so the frameworks are not included in analysis below. For a full presentation of the frameworks, see Appendix S5.

\section{Fully Defined Frameworks}

\section{IPCC}

The IPCC framework recognizes vulnerability to climate change as having three dimensions: Exposure to climate-induced shocks (a biophysical phenomenon); the Sensitivity of the unit of analysis to such shocks (both a social and biophysical phenomenon); the Adaptive Capacity to deal with such shocks (a social phenomenon). Application of the framework often, but not always, creates a context-specific index of vulnerability from measures of these three dimensions. Under the IPCC framework, vulnerability is defined as 'the degree to which a system is susceptible to, or unable to cope with, adverse effects of climate 
change, including climate variability and extremes. Vulnerability is a function of the character, magnitude, and rate of climate variation to which a system is exposed, its sensitivity, and its adaptive capacity' (Ref 62, p. 306). Twelve articles in our sample used this framework. ${ }^{9,13,19,54,62-69}$

\section{Patterns of Smallholder Vulnerability}

The Patterns of Smallholder Vulnerability framework uses the same construct as the IPCC, but offers a substantial elaboration of smallholders' adaptive capacity, specifically on coping capacity to adjust to weather extremes, manage damage or explore alternative livelihood opportunities. ${ }^{70}$ This framework applies the methodology of cluster pattern analysis as a way to deliver useful insights into recurrent combinations of measurements based on similarities among units of analysis, in cases where such a grouping exists. The final dimension of the framework is around how vulnerability (as manifested by its three components) affect the four primary dimensions of food security: food availability, access, stability of supply and access, and utilization of food. ${ }^{70}$

\section{Vulnerability as Expected Poverty, with Extensions}

The Vulnerability as Expected Poverty (VEP) framework conceives of vulnerability as when the unit of analysis (usually a household) becomes or remains poor in the future, given expected risk of experiencing shocks. It is an econometric approach that makes forward projections based on cross-sectional data and associated risks of climatic (and sometimes non-climatic) stress. In some cases, assessments of vulnerability based on expected poverty are then regressed against a series of socioeconomic data to identify predictors of vulnerability.

Extension 1: This variant focuses on a household's current and projected future food security status, ${ }^{71-73}$ rather than current and projected future levels of poverty, usually measured through consumption, as described above.

Extension 2: This variant includes multi-level analysis, wherein projections are made for units of analysis at two different scales (usually household and community/local), and analysis is done of differences between units at different scales. ${ }^{74,75}$

The VEP framework makes ex-ante estimates of a household's probability of becoming or remaining poor in the face of environmental or economic shocks through exploration of socio-economic backgrounds of households, and biophysical data on expected environmental conditions. Importantly, this estimate is made before uncertainty regarding these conditions has been resolved. To clarify how these approaches articulate, an 'axiomatic approach' has been used in one case to the analyze individual and clustered vulnerability. ${ }^{76}$ The framework integrates aspects like the household vulnerability index,${ }^{77}$ food insecurity, ${ }^{57}$ and expected future food security and nutritional status. ${ }^{71}$ Another important construct is around shocks, both household-specific idiosyncratic shocks and covariate shocks correlated across households within communities, ${ }^{75}$ highlighting how those have different causal mechanisms and aggregate effects.

\section{Conceptualizations and Constructs}

After coding the final pool of articles, 123 adequately operationalized central constructs were identified by term (e.g., vulnerability), of which roughly 100 appear in only one article. Further scrutiny of construct definitions resulted in five frequently occurring constructs being split into nine. Although the same terms were used, the definitions varied markedly across the frameworks. The most significant splits were found in the term 'vulnerability' which was used by 14 authors. After inspection, two main clusters could be detected (broadly corresponding to the IPCC definition, and the construct as used in the VEP framework), in addition to some poorly defined uses of the term.

Furthermore, 27 constructs labeled with different terms were merged into eight because, though the terms used varied, definitions revealed that they were talking about the same object. For example, the following constructs were merged: 'expected poverty ${ }^{, 78}$; 'household vulnerability as expected poverty" ${ }^{\text {"77}}$; household vulnerability to poverty ${ }^{74}$; 'rural household vulnerability" ${ }^{, 79}$; 'vulnerability. ${ }^{, 76,78}$

Finally, there were 39 article-specific constructs that could not be compared because definitions were not provided. Among those who provided construct definitions, many were unspecific or otherwise difficult to work with. For example, while many studies referred to the IPCC when introducing their constructs, they often produced rudimentary, circular or self-referential definitions of the child constructs, 'Exposure is the nature and degree to which a system is exposed to significant climatic variations' (Ref 68 , p. 11).

Similarly, comparison between construct definitions was made difficult by some authors' tendency to describe the theoretical phenomenon that they are trying to represent with that concept, while others lean more toward describing what data they will use to measure the concept. For example, the most challenging instance of identifying equivalence was 
between Westerhoff and Smit's definition of adaptation strategy and Eakin et al.'s definition of Impacts and responses to Hurricane Stan by coffee farmers. These constructs were assessed to be equivalent and merged.

Adaptations, or adaptive strategies, employed by individuals or groups are depicted as being mediated through their relative adaptive capacities, indicating that adaptations may or may not be accessed according to the distribution of various types of resources such as physical or social capital. (Ref 60, p. 321)

In this paper, we document household responses to a climatic shock, Stan, to gain insight into how natural resource-dependent communities move to secure their livelihoods following significant loss, the implications of household responses for coffee farming as a 'domain of attraction,' as well as to highlight those aspects of household choices and perceptions that may be indicative of resilience at broader scales. (Ref 49, p. 477)

Although definitions were provided in both cases, the different formats, levels of detail, and different orientations made the comparison between them, the decision to merge, and the subsequent cross-check in the team, quite difficult. A final set of core constructs and definitions is provided in Appendix S6.

\section{Operationalizations}

The common claim of papers to assess a state of vulnerability was unpacked in terms of how they operationalized the frameworks and constructs used to assess vulnerability, because these are only made scientifically meaningful by the ways that they are constituted through empirical data. Given the centrality of the IPCC in climate change research and policy, it is not surprising that the IPCC framework is the most prevalent. However, the IPCC framework defines its three key dimensions in very broad terms, leaving it up to individual researchers to operationalize them as they see fit. The diversity of approaches we found under the rubric of IPCC suggests that researcher's common invocation of the IPCC framework does not reliably predict common or even compatible practice. Among the articles that actually defined IPCC constructs, the operationalizations of 'exposure' and 'sensitivity' were relatively consistent, with exposure drawing on meteorological data and sensitivity capturing the degree to which climate phenomenon affect key biophysical processes (i.e., crop or pasture productivity). There was, however, substantially more variability in how researchers operationalized adaptive capacity. Definitions of adaptive capacity, as shown in Table 3, range from direct quotes from the broad IPCC language to fairly specific descriptions of constituent aspects.

A key dimension of how researchers operationalize their vulnerability frameworks is how they deal with the unit of measure, and the degree to which they approach vulnerability and adaptive capacity as emergent properties of systems (outcomes) versus as dynamic processes that occur through human agency and social practices. While most of the 13 definitions of adaptive capacity stay at the level of 'systems,' two papers indicate a clear orientation on actors and agency as central to their definitions of vulnerability, representing an important variation on the choice of how to conceptualize vulnerability. ${ }^{49,67}$ For example, adaptive capacity is most often characterized as a static dimension of a system, such as 'the ability of a system to adjust to climate change,' operationalized as 'a function of asset possession by the households' (Ref 68, p. 12), it is elsewhere characterized as something that is enacted rather than possessed: 'a latent property, which can be activated when people exercise their agency' (Ref 47, p. 15). However, while human agency is an important component of adaptive capacity, it is not a well-understood phenomenon nor effectively integrated into most measures (Ref 52, p. 873). It is elsewhere emphasized that a system's adaptive capacity 'is generated from the implementation of adaptation and interventions. ${ }^{, 47,51,70}$ While this does signal the importance of agency, it is unspecified who is responsible for interventions, and strongly implies that adaptive capacity is primarily located in processes of planned change through policy and development initiatives. Looking across the definitions, other factors specified as constituents of adaptive capacity include ownership of various assets, social support networks, learning networks, access to technology, institutional flexibility, governance structures and practices, DFID's sustainable livelihood components, and health status. These constructs are themselves extremely broad and variably operationalized.

Table 4 describes the operationalizations of adaptive capacity offered from the small subset of articles that provided sufficient information to link interpretable individual research methods to the construct 'adaptive capacity' and which have been assessed in our review as empirically valid (see transparency and validity assessment). There are several items that appear on the table multiple times, such as livelihood diversification, education levels, irrigation, dependency ratio, and farm size, perhaps indicating 
TABLE 3 | Definitions of Adaptive Capacity

\begin{tabular}{|c|c|}
\hline Author & Definition \\
\hline Antwi-Agyei et al. ${ }^{63}$ & $\begin{array}{l}\text { Adaptive capacity in the context of climate change has been defined by the Ref } 80, p .869 \text {, as 'the ability of a } \\
\text { system to adjust to climate change (including climate variability and extremes) to moderate potential } \\
\text { damages, to take advantage of opportunities, or to cope with the consequences.' Adaptive capacity } \\
\text { connotes some positive attributes of a system that enable it to reduce the adverse impacts (vulnerability) } \\
\text { associated with climate change. }\end{array}$ \\
\hline Baca et al. ${ }^{64}$ & $\begin{array}{l}\text { In contrast, adaptive capacity is defined as a system's ability to adjust to climate change in order to reduce or } \\
\text { mitigate possible damage. }{ }^{3} \text { Adaptive capacity is dynamic, and depends partly on the society productive } \\
\text { base, such as: natural and artificial assets, social benefits and networks, human capital and institutions, } \\
\text { governance, national income, health and technology, }{ }^{2} \text { and how much capability a society has to adapt to } \\
\text { the changes so as to maintain, minimize loss of, or maximize gain in welfare. }\end{array}$ \\
\hline Berkes and Ross ${ }^{47}$ & $\begin{array}{l}\text { Adaptive capacity is the capacity of actors in a system to influence resilience, }{ }^{82} \text { and often works through social } \\
\text { networks and learning communities. }{ }^{83}\end{array}$ \\
\hline & $\begin{array}{l}\text { We view adaptive capacity as a latent property, which can be activated when people exercise their agency. The } \\
\text { processes by which this occurs have not been well explored. }\end{array}$ \\
\hline CARE $^{65}$ & $\begin{array}{l}\text { The ability of a system to adjust to climate change (including climate variability and extremes) to moderate } \\
\text { potential damages, to take advantage of opportunities, or to cope with the consequences. }\end{array}$ \\
\hline $\begin{array}{l}\text { Eakin and } \\
\text { Bojórquez-Tapia }{ }^{19}\end{array}$ & $\begin{array}{l}\text { Local capacity to address climatic risk has been described as a function of indicators measuring access to } \\
\text { information, technology, wealth and finance, and institutional resources (such as subsidies or other forms of } \\
\text { external support), and is sign measuring access to information, technology, take advantage of opportunities, } \\
\text { or to cope with the consequences. }{ }^{84}\end{array}$ \\
\hline Füssel and Klein ${ }^{62}$ & $\begin{array}{l}\text { Adaptive capacity: The ability of a system to adjust to climate change (including climate variability and } \\
\text { extremes) to moderate potential damages, to take advantage of opportunities, or to cope with the } \\
\text { consequences. }\end{array}$ \\
\hline Hahn et al. ${ }^{54}$ & Adaptive capacity is the system's ability to withstand or recover from the exposure. ${ }^{85}$ \\
\hline Jamir et al. ${ }^{66}$ & $\begin{array}{l}\text { As per the IPCC's definition and framework, vulnerability is understood as a function of three components- } \\
\text { exposure, sensitivity and adaptive capacity. Vulnerability is defined as 'the degree to which a system is } \\
\text { susceptible to or unable to cope with, adverse effects of climate change, including climate variability and } \\
\text { extremes's6 }\end{array}$ \\
\hline Luers et al. ${ }^{9}$ & $\begin{array}{l}\text { We define adaptive capacity as the extent to which a system can modify its circumstances to move to a less } \\
\text { vulnerable condition (Figure } 1(\mathrm{c}) \text { ). We quantify adaptive capacity }(A) \text { as the difference in the vulnerability } \\
\text { under existing conditions and under the less vulnerable condition to which the system could potentially } \\
\text { shift: } A=V \text { (existing conditions) - V (modified conditions) }\end{array}$ \\
\hline Marshall $^{51}$ & $\begin{array}{l}\text { It refers to the ability of individuals or communities to adapt to adversity and stressful life-events by } \\
\text { 'reorganizing' through networks or institutions that learn, store knowledge and experience and are creative, } \\
\text { flexible and novel in their approach to problem solving. }{ }^{87-89}\end{array}$ \\
\hline Piya et al. ${ }^{68}$ & $\begin{array}{l}\text { Adaptive capacity is the ability of a system to adjust to climate change including climate variability and } \\
\text { extremes, to moderate the potential damage from it, to take advantage of its opportunities, or to cope with } \\
\text { its consequences. Selection of indicators for adaptive capacity is based on the DFID sustainable livelihoods } \\
\text { framework, whereby adaptive capacity is taken to be a function of asset possession by the households. }{ }^{90,91}\end{array}$ \\
\hline Sietz et al. ${ }^{70}$ & $\begin{array}{l}\text { The adaptive capacity of smallholders (the term as used in this study encompasses the coping capacity) } \\
\text { describes the ability to adjust to weather extremes, manage damages or explore alternative livelihood } \\
\text { opportunities. }\end{array}$ \\
\hline Tesso $^{52}$ & $\begin{array}{l}\text { According to Füssel and Klein, the risk-hazard framework (biophysical approach) corresponds most closely to } \\
\text { sensitivity in the IPCC terminology while the adaptive capacity (broader social development) is largely } \\
\text { consistent with the socio-economic approach. }{ }^{18} \\
\text { In the framework, capacity is generated from the implementation of adaptation and mitigation interventions. }{ }^{18}\end{array}$ \\
\hline
\end{tabular}

some consensus on their importance. However, it is noteworthy that the same variable is often used to operationalize different constructs. For example, 'Livestock' are variously treated as 'Natural Capital' or 'Financial Capital'; both 'Credit' and 'Membership in Community Organization' are treated as 'Social Capital' and 'Financial Capital,' indicating less consensus on the links between empirical foundations 
TABLE 4 | Operationalizations of Adaptive Capacity (from Ref 35)

\begin{tabular}{|c|c|c|c|}
\hline Child Construct (level 1) & Child Construct (level 2) & Measures & Articles \\
\hline \multirow[t]{25}{*}{ Livelihood assets } & Social capital & Community organization membership & Piya et al. ${ }^{68}$ \\
\hline & & Access to credit & \\
\hline & Physical capital & Irrigation & Antwi-Agyei et al. ${ }^{63}$ \\
\hline & & Communication devices & \\
\hline & & Type of house & Piya et al. ${ }^{68}$ \\
\hline & & Communication devices & \\
\hline & & Distance to road & \\
\hline & & Irrigation & \\
\hline & Natural capital & Farm size & Antwi-Agyei et al. ${ }^{63}$ \\
\hline & & Tenure system & \\
\hline & & $\%$ of productive land & Piya et al. ${ }^{68}$ \\
\hline & & Livestock & \\
\hline & Financial capital & Credit & Antwi-Agyei et al. ${ }^{63}$ \\
\hline & & Livestock & \\
\hline & & Remittances & \\
\hline & & Household income & Piya et al. ${ }^{68}$ \\
\hline & & Livelihood diversification & \\
\hline & & Household savings & \\
\hline & & Livestock & \\
\hline & & Membership of community orgs & \\
\hline & Human capital & Education level & Antwi-Agyei et al. ${ }^{63}$ \\
\hline & & Health status & \\
\hline & & Education & Piya et al. ${ }^{68}$ \\
\hline & & Dependency & \\
\hline & & Trainings & \\
\hline \multirow{10}{*}{$\begin{array}{l}\text { Socio-demographic profile; } \\
\text { livelihood strategies; social } \\
\text { network }\end{array}$} & Socio-demographic profile & Dependency ratio & Hahn et al. ${ }^{54}$ \\
\hline & & Female-headed households & \\
\hline & & Uneducated headed households & \\
\hline & & Households with orphans & \\
\hline & Livelihood strategies & Households working elsewhere & Hahn et al. ${ }^{54}$ \\
\hline & & Livelihood diversification & \\
\hline & & Agriculture dependent household & \\
\hline & Social network & Receive/give ratio & Hahn et al. ${ }^{54}$ \\
\hline & & Borrow/lend ratio & \\
\hline & & Independent of local government & \\
\hline \multirow[t]{7}{*}{ Direct operationalizations } & & Number of cultivated production zones & Sietz et al. ${ }^{70}$ \\
\hline & & Crop area & \\
\hline & & Livestock units & \\
\hline & & Potato productivity & \\
\hline & & Quinoa productivity & \\
\hline & & Education level of household head & \\
\hline & & Local off-farm income and remittances & \\
\hline
\end{tabular}


and conceptual clarity than might be supposed in authors who draw on the livelihoods five capitals approach.

The papers that constitute the VEP framework define vulnerability in ways that emphasize how climate shocks contribute to impoverishment of households or communities. By emphasizing consumption level, food security or asset ownership as the operative measurements of vulnerability, papers within the VEP framework propose that projected poverty is the meaningful negative outcome related to climate vulnerability (Table 5). Subsequent operationalizations of 'poverty' (Table 6) rely on household financial measures as well as access to production technologies. Transparency of the empirical foundations was a challenge in this group as they made extensive use of citations to specify details.

This section has presented the fully operationalized frameworks in terms of how they are conceptually constituted and how some of the key constructs are then operationalized through use of empirical data. Space precludes full elaboration of the uneven frameworks and all constructs, but that information, including options among fully transparent operationalizations of core constructs, can be found in great detail elsewhere (Ref 52, p. 873). However, many of the insufficiently operationalized frameworks appear to deal with overlapping constructs, particularly variants on 'livelihoods,' 'household assets' and 'poverty.'

\section{Data Collection Methods}

Looking one step beyond the measures used, Table 7 assesses the nature of actual data collected (as reported) to constitute these measures. In particular, it explores the degree to which data are based upon direct observational measure, like precipitation data from a weather station, versus reported data, which is subjectively mediated though informants' responses in interviews or questionnaires. It is essential to note that 'reported' and 'observational' should not be conflated with 'qualitative' and 'quantitative.' Instead these categories pertain to the methodological construction of evidence.

There were a total of 57 constructs whose measurements were entirely taken by asking informants questions. Of these 57 constructs, 16 were reported (e.g., informant's perception of risk) while the remaining 41 were direct observational (e.g., what is the actual climate variability). Again, some constructs appear in multiple categories because different articles approach them in a variety of ways. For example, different studies measured 'adaptive capacity' through a survey questionnaire, through combination of survey and meteorological/remote-sensing data and solely through meteorological/remote-sensing data. Analysis of methods for the aggregation of collected data is beyond the scope of this paper, but would be a worthwhile subject for subsequent research.

TABLE 5 | Definitions of Vulnerability to Expected Poverty Variants

\begin{tabular}{|c|c|}
\hline Authors (variant) & Definition \\
\hline $\begin{array}{l}\text { Deressa et al. } \\
\text { (Expected poverty) }\end{array}$ & $\begin{array}{l}\text { This method is based on estimating the probability that a given shock or set of shocks will move } \\
\text { household consumption below a given minimum level (such as a consumption poverty line) or } \\
\text { force the consumption level to stay below the minimum if it is already below this level. }{ }^{92}\end{array}$ \\
\hline $\begin{array}{l}\text { Chhinh and Poch } \\
\text { (household vulnerability as } \\
\quad \text { expected poverty) }\end{array}$ & $\begin{array}{l}\text { Household vulnerability as expected poverty is defined as the probability that households will move } \\
\text { into poverty given certain environmental shocks, current poverty status and household } \\
\text { characteristics of respondents. }\end{array}$ \\
\hline $\begin{array}{l}\text { Échevin }{ }^{74} \\
\text { (household vulnerability to } \\
\text { poverty) }\end{array}$ & $\begin{array}{l}\text { We can define vulnerability to poverty as the probability of falling into poverty when one's } \\
\text { consumption/income falls below a predefined poverty line. }\end{array}$ \\
\hline $\begin{array}{l}\text { Sarris and Karfakis }{ }^{79} \\
\text { (rural household vulnerability) }\end{array}$ & $\begin{array}{l}\text { Thus a household is said to be vulnerable to the outcome of a risk event, if it does not have } \\
\text { sufficient resources to adequately contend with the risk event. In other words, the extent to } \\
\text { which a household is vulnerable to a risk event, namely the extent to which the household can } \\
\text { become and/or remain poor or food deprived, depends on the size of the risk event and how } \\
\text { effective the household is in managing the risk event. } \\
\text { Considers vulnerability as the probability of consumption falling below a poverty threshold. }{ }^{93}\end{array}$ \\
\hline $\begin{array}{l}\text { Calvo and Dercon } \\
\text { (vulnerability to poverty) }\end{array}$ & $\begin{array}{l}\text { In this article, we explore the notion of vulnerability to poverty, closely linked with the magnitude } \\
\text { of the threat of poverty, measured ex-ante, before uncertainty has been resolved. } \\
\text { [...] } \\
\text { Remarking that we are interested in vulnerability to poverty will also be useful to pre-empt any } \\
\text { confusion with vulnerability to downfalls in wellbeing. Our reference point is an absolute poverty } \\
\text { norm (e.g., as in Refs } 94,95) \text {, and not the initial individual position. }\end{array}$ \\
\hline
\end{tabular}


TABLE 6 | Operationalizations of Poverty

\begin{tabular}{|c|c|c|}
\hline & Measures & Articles \\
\hline \multirow[t]{3}{*}{ Direct operationalizations } & Income and 4 different poverty lines & Deressa et al. ${ }^{78}$ \\
\hline & Annual per capita total expenditure & Sarris and Karfakis ${ }^{79}$ \\
\hline & Annual per capita total income & \\
\hline \multirow[t]{7}{*}{ Cereal production } & Arable land owned & Mutsvangwa $^{72}$ \\
\hline & Crops grown and areas allocated to the crops & \\
\hline & Yields obtained & \\
\hline & Farming implements available & \\
\hline & Availability of draft power & \\
\hline & Livestock owned & \\
\hline & Crop management practices & \\
\hline \multirow[t]{5}{*}{ Excluded } & & Calvo and Dercon ${ }^{76}$ : Not transparently operationalized \\
\hline & & Chhihn and Poch ${ }^{77}$ : Not transparently operationalized \\
\hline & & Capaldo et al. ${ }^{71}$ : Not transparently operationalized \\
\hline & & Échevin ${ }^{74}$ : Not Valid/feasible \\
\hline & & Gunther and Harttgen ${ }^{75}$ : Not Valid/feasible \\
\hline
\end{tabular}

\section{DISCUSSION}

The findings of this review indicate a broad consensus around conceptual frameworks for local-level agricultural vulnerability that integrate social and biophysical factors as elements. This is a significant shift, considering the greater prevalence of more hazard based approaches of the late 1990s and early 2000s. Given its political importance, it is predictable that there has been substantial convergence around the language of the IPCC vulnerability framework. Despite integrating biophysical and social dynamics, the IPCC framework, as used, privilege climatic factors as the primary point of reference in the understanding of vulnerability. Unlike the IPCC vulnerability framework, VEP does not structurally assume that shocks arise from climate change nor that climate change is the most important reference point for understanding vulnerability. Instead, VEP, as used, is fairly neutral in recognition of dynamics relevant to the creation and perpetuation of poverty. This puts climate shocks on the same level with other hazards while using economic outcomes as the dependent variable. Coming from outside of the climate change literature, the papers analyzed in our study represent a sample of VEP studies that integrate climate as relevant to poverty and food security outcomes.

These differences between IPCC and VEP conceptual frameworks for climate change vulnerability have important implications for how climate vulnerability reduction efforts are engaged. Even if application of the IPCC framework is empirically valid and objectively sound, the assumption of climate as the primary vulnerability hazard risks creating substantive mismatches between vulnerability reduction interventions and local actors' interests and priorities, where climate change may not be a primary vulnerability concern. ${ }^{35,36}$ On the other hand, by focusing on economic outcomes at the household and community levels as the primary reference point for understanding vulnerability, and by not assuming climate the as the primary hazard that exacerbates vulnerability, VEP approaches appear more likely to closely approximate rural actors' perspectives.

Looking beyond the basic IPCC vocabulary into the constitution of that framework in practice reveals that the apparent conceptual convergence may be more superficial than substantive. Among the studies using IPCC framework reviewed, there is high degree of variability in exactly what those studies reported empirically examining. The labels 'IPCC framework' 'exposure,' 'sensitivity' and 'adaptive capacity' seemed at times to be the only things shared across these studies. It is noteworthy, however, that the variability within the IPCC-based studies was not evenly distributed, with relatively greater agreement found in exposure and sensitivity and greater divergence found in adaptive capacity.

The VEP papers provide approaches that allow climate vulnerability to be understood in the context of non-climatic drivers and broader contextual factors that produce the social circumstances of 
TABLE 7 | Nature of Actual Data Collected

\begin{tabular}{|c|c|c|c|}
\hline \multicolumn{4}{|l|}{ Reported Measures } \\
\hline Adaptive capacity & Diversified livelihood activities & Householder working far & Natural water source \\
\hline Ag. dependent households & Don't save crops & Human capital & No warning of disaster \\
\hline Average precipitation & Don't save seeds & Idiosyncratic shocks & Non-climatic stress \\
\hline Borrow-lend ratio & Family with chronic illness & Impacts \& resp. to disaster & Non-labor prod. assets \\
\hline Cereal production & Farmer perceptions & Inconsistent water supply & $\%$ female-headed house. \\
\hline Climate change & Financial capital & Independent of government & Perception of adiha farmers \\
\hline Climate variability & Flood, drought, cyclone & Injury or death fm. disaster & Physical capital \\
\hline Community & Food from family farm & Inverse water stored & Proximity to health facility \\
\hline Community level & Food security & Labor & Proximity to water source \\
\hline Covariate shocks & Household characteristics & Livelihood diversification & Receive-give ratio \\
\hline Crop diversity & Household consumption & Livelihood sensitivity & Social capital \\
\hline Crop sensitivity & Household level & Malaria exposure-prevention & Struggle for food \\
\hline Dependency ratio & Household level resilience & Maximum temperature & Uneducated head house \\
\hline \multirow[t]{2}{*}{ Determinants of resilience } & Households with orphans & Natural capital & Water conflict \\
\hline & & & Week illness \\
\hline $\begin{array}{l}\text { Probable Reported } \\
\text { Measures }\end{array}$ & $\begin{array}{l}\text { Mixed Reported- } \\
\text { Observational Measures }\end{array}$ & Observational Measures & Not Interpretable \\
\hline Agricultural vulnerability & Adaptation strategy & Adaptive capacity & Adaptive capacity \\
\hline Biophysical vulnerability & Adaptive capacity & Drought & Community level \\
\hline Current exposure to risk & Economic expectations & Dynamic natural resource base & Covariate shocks \\
\hline Current socio-econ. chars & Exposed \& sensitive to cc & Exposure & Entity \\
\hline Demographic vulnerability & Financial capital & Meteorological observation & Exposure \\
\hline Financial capital & Social connectivity & Minimum temperature & Household level \\
\hline Human capital & & Resilient/vulnerable communities & Idiosyncratic shocks \\
\hline Natural capital & & Risk of climate change & Institutional environment \\
\hline Physical capital & & Sensitivity & Stimulus \\
\hline Sensitivity & & System state vs damage threshold & Structural poverty \\
\hline Social capital & & Threshold to damage & \\
\hline Socio-econ. vulnerability & & Wellbeing & \\
\hline Vulnerability threshold & & & \\
\hline
\end{tabular}

vulnerability and poverty more generally. Bracketing out climate vulnerability and adaptation from other dynamics of social and environmental change will likely produce poor prescriptions for how to engage in adaptation. Where the IPCC framework might ask how climate shocks drive people to poverty, VEP asks how the already complex socio-environmental dynamics of poverty creation interact with the additional stressor of climate shocks. By assuming that vulnerability generally emerges through complex and multi-faceted social processes, VEP opens doors for questions that do not assume the primacy of climate as a driver of vulnerability. While it is not always explicit in the VEP publications, they imply that other social mechanisms contributing to, intersecting with or compounding climate vulnerability are relevant for understanding how people engage in adaptation. As such, we propose that the field of climate vulnerability research will benefit from greater reflection on how to integrate non-climate vulnerability hazards in a more nuanced fashion. This should improve the applicability of vulnerability research to policy development because many of these nonclimate vulnerability drivers are more salient in the priorities and practices of rural communities around the world.

One weakness in both IPCC and VEP frameworks is the treatment of human agency. Few of the articles reviewed explicitly acknowledge agency, and when they do, it is usually in very broad terms. The 
preoccupation with adaptive capacity as a quality of 'a system' elides an understanding of adaptation as a process that is ultimately enacted by people, both at individual and collective scales. ${ }^{96}$ While index based vulnerability assessments may be useful in providing an overview of adaptive capacity, they would benefit from complementary analysis of adaptation processes based in human agency. This would enable recommendations that are attuned to ongoing practices and dynamics rather than just a set of measures.

In analyzing across vulnerability studies, adaptive capacity presents the greatest challenge for those who wish to aggregate results. The degree of variability in the operationalization of adaptive capacity reflects how researchers struggle to describe the extraordinary complexity of how social systems and social practices mediate peoples' experience of environmental change. But, if we accept that frameworks and constructs are ultimately substantiated through operationalizations and measurements, the diversity effectively suggests that each IPCC-based study proposes its own mutually incommensurate framework and constituent constructs for 'adaptive capacity.' As such, the current state of the field is not sufficiently coherent or robust to identify scientifically supported approaches toward interventions aimed at improving adaptive capacity across diverse locations. In terms of informing efforts to improve adaptive capacity, it is only a slight exaggeration to say that the research community is proposing that adaptive capacity is whatever we want it to be from moment to moment, with uneven regard for consistency between the conceptual language and the concrete measures. This makes adaptive capacity the greatest emerging challenge for the field. ${ }^{97}$

Having outlined the high degree of heterogeneity at the conceptual and operational levels, it may seem superfluous to reflect upon the precise methodological choices made in vulnerability research. However, while conceptual coherence is in many ways a higher order concern than methodological consistency, critical analysis of the actual methods and measures used to make the constructs concrete remains an important part of developing 'robust and credible' measurements. ${ }^{22,98}$ The degree of heterogeneity in measurement choices in reviewed papers indicates both creative engagement in how to make the topic researchable and the inherent context specificity of vulnerability research. Given the multi-faceted nature of the vulnerability construct (particularly adaptive capacity within it), multi-method triangulation is an inevitable aspect of any credible research. In the context of climate change vulnerability and adaptive capacity, research methods that employ reported and observed data can both be valuable. However, the integration of reported and observed measures complicates validity, precision and error within any research project. Both require context appropriate interpretation by researchers, but reported and observed data are vulnerable to different kinds of errors. Inconsistencies in how and when reported or observed data are used become even more problematic when attempting to make valid comparisons across projects, even ones that apply the same conceptual framework. Lack of transparency in data collection and integration methods further complicate our ability to evaluate research practices in this tricky, but fundamentally important, sphere of research activities. Based on this finding, we strongly encourage researchers within the field to engage in critical discussions around the effective and valid integration of observed and reported data.

Vulnerability is rightly recognized as a complex and context-specific phenomenon, and any valid study of vulnerability must be attuned to the particularities of place. Effective integration of multiple forms of data into a coherent vulnerability framework is thus important for scientific credibility. However, for vulnerability research to become more relevant to policy initiatives and technical innovations that aim to achieve widespread and demonstrable impact (i.e., reducing vulnerability through somehow improving adaptive capacity), it needs to get beyond the particularism of individual sites, moments, research projects and approaches without falling prey to a rigid orthodoxy that compromises validity in the interest of comparability. This requires vibrant, nuanced and reflexive discussion within the field regarding research practices around frameworks, constructs, operationalizations and methodologies, including the reporting thereof. By dissecting and analyzing these aspects of vulnerability studies, this paper aims to stimulate the discussions that will advance the field of vulnerability research in years to come.

\section{CONCLUSIONS AND RECOMMENDATIONS}

If climate vulnerability research strives to make the complexity and abstractness of vulnerability more tractable in order to effectively inform efforts to reduce vulnerability (policies, etc.), then there is a need for coherent frameworks, commensurate instruments and transparent reporting. One of the conditions required for science is that inquiry today should be able to make good use of the work of those who 
have gone before. Absent clarity, it is not possible for our work to rise to the standard of science. Returning to Pasteur's analogy, this risks rendering research's harvest inedible. This review started with the basic scientific assumption that quality and coherence improves research's collective ability to confidently inform practical interventions aimed at vulnerability reduction. It follows that a conceptually robust and empirically rigorous body of commensurable studies will strengthen the field's ability to support vulnerability reduction efforts. Not only will it enable more confident guidance of interventions, it will also improve the capacity to track their efficacy in a consistent manner. The wisdom of and pathway toward this objective was outlined by leaders in the field over a decade ago. However, our review shows that while there has been some modest progress, there remains a long way to go toward achieving coherence, transparency and commensurability in vulnerability research.

This systematic review of local vulnerability to climate change in developing country agriculture was conducted to inform a transparent discussion around the various frameworks, operationalizations and methods used to research vulnerability. Without examining the application of vulnerability frameworks, constructs and methods in empirical detail, distilling generalizations about causal drivers of vulnerability risks being misleading and programmatic interventions addressing vulnerability risk being poorly informed and thus less effective.

Despite some general consolidation around the IPCC framework and vocabulary, vulnerability research maintains substantial conceptual and methodological heterogeneity, underlining that concerns from a decade ago about incoherence and incommensurability are still relevant today. The profusion of research approaches indicates a positive development in terms of scientific innovation, but simultaneously complicates the aggregation of findings needed for progress on the empirical understanding of vulnerability's dynamics and drivers as well as theorization of vulnerability in general. Furthermore, with vulnerability reduction through improvement of adaptation capacity rising on the global political agenda, it is increasingly important for development and policy institutions to design sensible interventions and to be able to show what impact their interventions have. This in turn requires research frameworks and instruments for programming and evaluation that are sufficiently commensurate across diverse contexts, while remaining sensitive to site specificity.

This systematic review has described a range of approaches by which vulnerability is being studied and summarizes a range of options for a programmatic approach that enable cross-site and cross-case comparison. This review found many theoretical and methodological options whose provenance and quality we could not verify due to uneven reporting. As with any monitoring and evaluation system for a complex domain, both the theoretical frameworks and the research methods used in examining vulnerability require systematic and rigorous testing in order to produce theory and methods that can be used with the confidence. Because we were unable to reliably identify evidence required to assess the empirical merit of much of what we reviewed, we are not able to recommend a particular framework, approach, or methodological system for wholesale institutional adoption.

One key choice in vulnerability research is whether the objective is to describe vulnerability as an outcome/state-of-being through a set of measures, or to analyze the production of vulnerability as a process through which numerous determinants and drivers interact to cause specified outcomes. Researching outcome measures of vulnerability vs. processual drivers of vulnerability implies substantially different research designs and programmatic applications, yet our analysis found that the two approaches were frequently conflated, unspecified or indiscernible. Like our identification of methodological and conceptual heterogeneity, our identification of ambiguity in the objectives of vulnerability research is not entirely new. ${ }^{2,3,8,10}$ The persistence of ambiguous reporting, however, indicates a need to reiterate prior recommendations that research in the field of vulnerability studies should be extremely explicit and precise about its objectives. If carefully considered in research design and clearly specified in reporting, addressing the six following questions can go a long way toward reducing ambiguity in vulnerability research:

1. Is this system vulnerable?

2. To what is this system vulnerable?

3. How vulnerable is this system?

4. What is causing this system to be vulnerable?

5. How is vulnerability distributed within the system?

6. What is causing the observed distribution of vulnerability within the system?

Both vulnerability as outcome and vulnerability as process can theoretically be studied by analyzing across scales, ranging from households, to communities, to regional and national governments. 
However, each of these options suggests very different conceptual tools, research questions, data sets and kinds of conclusions that can be drawn. What is most important at this point in the maturation of vulnerability research is for researchers to be painstakingly clear and precise in their reporting practices. Clarity and transparency in conceptual, methodological and analytical choices-and the reporting thereof-will enable more robust assessment of the significance, the quality and comparability of research findings. This, in turn, will promote a more empirically informed theorization of vulnerability.

Looking beyond theory, vulnerability research has long been intent on improving its policy relevance. Since the early 2000s, it has been recognized that this is contingent upon two overarching factors: (1) improving the scientific coherence and credibility of the research field as a whole and (2) connecting the findings from vulnerability research with, and perhaps directly embedding them within, policy making processes. Both research and decision-making-policy making, development investment or interventions, research agenda setting, adaptation funding initiatives, climate finance structures, etc.-can be oriented at different geographic scales, creating a wide range of possible applications. However, without some degree of coherence in research practice, the policy relevance of vulnerability research will at best be limited to the direct engagements of specific research projects with specific policy processes. Without dismissing the value of direct, particularistic engagement, this indicates a lost opportunity for more robust synthetic analyses across multiple research projects and sites which can enable more effective programmatic application of vulnerability analyses.

While several reviews of vulnerability theory and methods have been produced, our use of a structured, rather than expert-based, review methodology contributes greater clarity and transparency to conversations on methodological development. ${ }^{16}$ The objective of this systematic review has been to provide a valid description of the key dimensions of heterogeneity within research on local-level agricultural vulnerability to climate stress, particularly those relevant to the commensuration required to support policy and programming. It is neither possible nor appropriate to promote rigid standardization in the field. Rather, our goal in describing this heterogeneity is to encourage collective reflection and deliberative discussion of the trade-offs between diversity and coherence in the field. This includes seeking opportunities for moving toward greater coherence where appropriate as well as making informed choices about when to maintain heterogeneity.

\section{ACKNOWLEDGMENTS}

We acknowledge the CGIAR Fund Council, Australia (ACIAR), Irish Aid, European Union, International Fund for Agricultural Development (IFAD), Netherlands, New Zealand, Switzerland, UK, USAID and Thailand for funding to the CGIAR Research Program on Climate Change, Agriculture and Food Security (CCAFS). We would particularly like to thank Phillip Thornton and Wiebke Förch of CCAFS' Policies and Institutions Flagship for directly supporting this systematic review project. We would also like to thank the panel of 28 vulnerability researchers who helped validate and refine our sample of publications to analyze. Finally, we are grateful for the insightful and persistent suggestions from 2 reviewers, which have substantially improved this article.

\section{REFERENCES}

1. Yamin F, Rahman A, Huq S. Vulnerability, adaptation and climate disasters: a conceptual overview. IDS Bull 2005, 36:1-14.

2. Adger WN. Vulnerability. Glob Environ Chang 2006, 16:268-281.

3. Eakin H, Luers AL. Assessing the vulnerability of social-environmental systems. Annu Rev Env Resour 2006, 31:365-394.

4. Füssel H-M. Vulnerability: a generally applicable conceptual framework for climate change research. Glob Environ Chang 2007, 17:155-167.
5. Brooks N. Vulnerability, risk and adaptation: a conceptual framework. Tyndall Centre Clim Change Res Working Paper 2003, 38:1-16.

6. Gallopín GC. Linkages between vulnerability, resilience, and adaptive capacity. Glob Environ Chang 2006, 16:293-303.

7. Kelly PM, Adger WN. Theory and practice in assessing vulnerability to climate change and facilitating adaptation. Clim Change 2000, 47:325-352.

8. Eriksen SH, O'Brien K. Vulnerability, poverty and the need for sustainable adaptation measures. Clim Policy 2007, 7:337-352. 
9. Luers AL, Lobell DB, Sklar LS, Addams CL, Matson PA. A method for quantifying vulnerability, applied to the agricultural system of the Yaqui Valley, Mexico. Glob Environ Chang 2003, 13: 255-267.

10. Turner BL, Kasperson RE, Matson PA, McCarthy JJ, Corell RW, Christensen L, Eckley N, Kasperson JX, Luers A, Martello ML, et al. A framework for vulnerability analysis in sustainability science. Proc Natl Acad Sci USA 2003, 100:8074-8079.

11. Giupponi C, Biscaro C. Vulnerabilities-bibliometric analysis and literature review of evolving concepts. Environ Res Lett 2015, 10:123002.

12. Hinkel J. "Indicators of vulnerability and adaptive capacity": towards a clarification of the science-policy interface. Glob Environ Chang 2011, 21:198-208.

13. Ionescu C, Klein RJT, Hinkel J, Kavi Kumar KS, Klein R. Towards a formal framework of vulnerability to climate change. Environ Model Assess 2009, 14:1-16.

14. UNFCCC. Compendium on methods and tools to evaluate impacts of, and vulnerability and adaptation to, climate change. 2008, 111. Available at: https://unfccc. int/files/adaptation/nairobi_workprogramme/co mpendium_on_methods_tools/application/pdf/200803 07_compendium_m_t_complete.pdf

15. Soares MB, Gagnon AS, Doherty RM. Conceptual elements of climate change vulnerability assessments: a review. Int J Clim Change Strat Manage 2012, 4:6-35.

16. O'Brien K, Eriksen S, Nygaard LP, Schjolden ANE. Why different interpretations of vulnerability matter in climate change discourses. Clim Policy 2007, 7:73-88.

17. Dhanapal G, Panda A. Climate change vulnerability assessment: gaps and challenges. Econ Pol Wkly 2014, 49:32-34.

18. Magnan AK. Climate change: metrics needed to track adaptation. Nature 2016, 530:160-160.

19. Eakin H, Bojórquez-Tapia LA. Insights into the composition of household vulnerability from multicriteria decision analysis. Glob Environ Chang 2008, 18:112-127.

20. Tonmoy FN, El-Zein A, Hinkel J. Assessment of vulnerability to climate change using indicators: a metaanalysis of the literature. WIREs Clim Change 2014, 5:775-792.

21. CASP. Systematic Review Checklist. Available at: http://media.wix.com/ugd/dded87_a02ff2e3445f4952 992d5a96ca562576.pdf.

22. Hinkel J, Bisaro A. A review and classification of analytical methods for climate change adaptation. WIREs Clim Change 2015, 6:171-188.

23. Thomas J, Harden A. Methods for the thematic synthesis of qualitative research in systematic reviews. BMC Med Res Methodol 2008, 8:45.
24. Dixon-Woods $M$, Bonas S, Booth A, Jones DR, Miller T, Sutton AJ, Shaw RL, Smith JA, Young B. How can systematic reviews incorporate qualitative research? A critical perspective. Qual Res 2006, $6: 27-44$.

25. Magarey JM. Elements of a systematic review. Int J Nurs Pract 2001, 7:376-382.

26. Wells K, Littell JH. Study quality assessment in systematic reviews of research on intervention effects. Res Soc Work Pract 2008, 19:52-62.

27. Berrang-Ford L, Ford JD, Paterson J. Are we adapting to climate change? Glob Environ Chang 2011, 21:25-33.

28. Thompson HE, Berrang-Ford L, Ford JD. Climate change and food security in sub-Saharan Africa: a systematic literature review. Sustainability 2010, 2:2719-2733.

29. Jones L, Champalle C, Chesterman S, Cramer L, Crane TA. Constraining and enabling factors to using long-term climate information in decision-making. Clim Policy 2016:1-22.

30. Ford JD, Keskitalo ECH, Smith T, Pearce T, BerrangFord L, Duerden F, Smit B. Case study and analogue methodologies in climate change vulnerability research. WIREs Clim Change 2010, 1:374-392.

31. Dubois C-A, D'Amour D, Pomey M-P, Girard F, Brault I. Conceptualizing performance of nursing care as a prerequisite for better measurement: a systematic and interpretive review. BMC Nurs 2013, 12:7. doi: 10.1186/1472-6955-12-7.

32. Le Reste JY, Nabbe P, Manceau B, Lygidakis C, Doerr C, Lingner H, Czachowski S, Munoz M, Argyriadou S, Claveria A, et al. The European general practice research network presents a comprehensive definition of multimorbidity in family medicine and long term care, following a systematic review of relevant literature. J Am Med Directors Assoc 2013, 14:319-325.

33. van der Lee J, Mokkink L, Grootenhuis M, Heymans H, Offringa M. Definitions and measurement of chronic health conditions in childhood a systematic review. JAMA 2007, 297:2741-2751.

34. Delaney A, Tamás PA, Crane TA, Chesterman S. Systematic review of methods in low-consensus fields: supporting commensuration through 'construct-centered methods aggregation' in the case of climate change vulnerability research. PLoS One 2016, 11:e0149071.

35. Delaney A, Chesterman S, Crane TA, Tamás PA, Ericksen P. A systematic review of local vulnerability to climate change: In search of transparency, coherence and compatibility. CCAFS Working Paper 2014. 97: 83. Available at: https://cgspace.cgiar.org/handle/ $10568 / 56692$.

36. Delaney A, Tamás P. Technical Report-a systematic review of local vulnerability to climate change: In search of transparency, coherence and comparability. 
CCAFS Working Papers 2014. 97: 791. Available at: https://cgspace.cgiar.org/handle/10568/56692.

37. Moher D, Liberati A, Tetzlaff J, Altman DG. Preferred reporting items for systematic reviews and meta-analyses: the PRISMA statement. Ann Intern Med 2009, 151:264-269.

38. Sandoval JA, Lucero J, Oetzel J, Avila M, Belone L, Mau M, Pearson C, Tafoya G, Duran B, Ríos LI, et al. Process and outcome constructs for evaluating community-based participatory research projects: a matrix of existing measures. Health Educ Res 2012, 27:680-690.

39. Glaser BG. The constant comparative method of qualitative analysis. Soc Probl 1965, 12:436-445.

40. Carroll C, Booth A, Leaviss J, Rick J. "Best fit” framework synthesis: refining the method. BMC Med Res Methodol 2013, 13.

41. Morse JM. Constructing qualitatively derived theory: concept construction and concept typologies. Qual Health Res 2004, 14:1387-1395.

42. Borgatti SP. Cultural domain analysis. I Quant Anthropol 1994, 4:261-278.

43. Gandure S, Walker S, Botha JJ. Farmers' perceptions of adaptation to climate change and water stress in a South African rural community. Environ Dev 2013, 5:39-53.

44. Mubaya CP, Njuki J, Mutsvangwa EP, Mugabe FT, Nanja D. Climate variability and change or multiple stressors? Farmer perceptions regarding threats to livelihoods in Zimbabwe and Zambia. J Environ Manage 2012, 102:9-17.

45. Da Silva S. Assessment of transparency, structure, and coherence: a systematic review of empirical research articles on social movements in Latin America; 2014.

46. Kampen J, Tamás PA. Should I take this seriously? A simple checklist for calling bullshit on policy supporting research. Qual Quant 2014, 48:1213-1223.

47. Berkes F, Ross H. Community resilience: toward an integrated approach. Soc Nat Res Int J 2013, 26:5-20.

48. Bogale A, Taeb M, Endo M. Land ownership and conflicts over the use of resources: implication for household vulnerability in eastern Ethiopia. Ecol Econ 2006, 58:134-145.

49. Eakin H, Benessaiah K, Baretta JF, Cruz-Bello GM, Morales H. Livelihoods and landscapes at the threshold of change: disaster and resilience in a Chiapas coffee community. Reg Environ Change 2012, 12: $475-488$.

50. Khan FA, Salman A. A simple human vulnerability index to climate change hazards for Pakistan. Int J Disaster Risk Sci 2012, 3:163-176.

51. Marshall NA. Understanding social resilience to climate variability in primary enterprises and industries. Glob Environ Chang 2010, 20:36-43.
52. Tesso G. Analysis of vulnerability and resilience to climate change induced shocks in North Shewa, Ethiopia. Agric Sci 2012, 03:871-888.

53. Ford J, Smit B. A framework for assessing the vulnerability of communities in the Canadian Arctic to risks associated with climate change. Arctic 2004, 57:389-400.

54. Hahn MB, Riederer AM, Foster SO. The livelihood vulnerability index: a pragmatic approach to assessing risks from climate variability and change-a case study in Mozambique. Glob Environ Chang 2009, 19:74-88.

55. Eakin H, Winkels A, Sendzimir J. Nested vulnerability: exploring cross-scale linkages and vulnerability teleconnections in Mexican and Vietnamese coffee systems. Environ Sci Policy 2009, 12:398-412.

56. Dasgupta A, Baschieri A. vulnerability to climate change in rural Ghana: mainstreaming climate change in poverty-reduction strategies. J Int Dev 2010, 22:803-820.

57. Misselhorn AA. What drives food insecurity in southern Africa? A meta-analysis of household economy studies. Glob Environ Chang 2005, 15:33-43.

58. Sallu SM, Twyman C, Stringer LC. Resilient or vulnerable livelihoods? Assessing livelihood dynamics and trajectories in rural Botswana. Ecol Soc 2010, 15:3. Available at: http://www.ecologyandsociety.org/vol15/ iss $4 / \operatorname{art} 3 /$.

59. Nkondze MS, Masuku MB, Manyatsi A. Factors affecting households vulnerability to climate change in swaziland: a case of Mpolonjeni Area Development Programme (ADP). J Agric Sci 2013, 5:108-122.

60. Westerhoff L, Smit B. The rains are disappointing us: dynamic vulnerability and adaptation to multiple stressors in the Afram Plains, Ghana. Mitig Adapt Strat Glob Chang 2008, 14:317-337.

61. Mengistu DK. Farmers' perception and knowledge on climate change and their coping strategies to the related hazards: case study from Adiha, central Tigray, Ethiopia. Agric Sci 2011, 02:138-145.

62. Füssel H-M, Klein RJT. Climate change vulnerability assessments: an evolution of conceptual thinking. Clim Change 2006, 75:301-329.

63. Antwi-Agyei P, Dougill AJ, Fraser EDG, Stringer LC. Characterising the nature of household vulnerability to climate variability: empirical evidence from two regions of Ghana. Environ Dev Sustain 2013, 15:903-926.

64. Baca M, Läderach P, Haggar J, Schroth G, Ovalle O. An Integrated framework for assessing vulnerability to climate change and developing adaptation strategies for coffee growing families in Mesoamerica. PLoS One 2014, 9:e88463. doi:10.1371/journal.pone.0088463. 
65. CARE. Climate Vulnerability and Capacity Analysis: Handbook, 2009. Available at: http://www. careclimatechange.org.

66. Jamir C, Sharma N, Sengupta A, Ravindranath NH. Farmers' vulnerability to climate variability in Dimapur district of Nagaland, India. Reg Environ Change 2013, 13:153-164.

67. Notenbaert A, Karanja SN, Herrero M, Felisberto M, Moyo S. Derivation of a household-level vulnerability index for empirically testing measures of adaptive capacity and vulnerability. Reg Environ Change 2013, 13:459-470.

68. Piya L, Maharjan KL, Joshi NP. Vulnerability of rural households to climate change and extremes: analysis of Chepang households in the Mid-Hills of Nepal. In: 2012 Conference, August 18-24, 2012. Foz do Iguacu, Brazil: International Association of Agricultural Economists; 2012.

69. Acosta-Michlik L, Espaldon V. Assessing vulnerability of selected farming communities in the Philippines based on a behavioural model of agent's adaptation to global environmental change. Glob Environ Chang 2008, 18:554-563.

70. Sietz D, Mamani C, Sabino E, Lüdeke MKB. Typical patterns of smallholder vulnerability to weather extremes with regard to food security in the Peruvian Altiplano. Reg Environ Change 2012, 12:489-505.

71. Capaldo J, Karfakis P, Knowles M, Smulders M. A model of vulnerability to food insecurity. ESA Working Paper, p 25; 2010.

72. Mutsvangwa EP. Climate change and vulnerability to food insecurity among smallholder farmers: a case study of Gweru and Lupane districts in Zimbabwe. Agric Econ 2011, MSc:121.

73. Bogale A. Vulnerability of smallholder rural households to food insecurity in Eastern Ethiopia. Food Security 2012, 4:581-591.

74. Échevin D. Characterizing poverty and vulnerability in rural Haiti: a multilevel decomposition approach. Munich Personal RePEc Archive, 2011, 31.

75. Günther I, Harttgen K. Estimating households vulnerability to idiosyncratic and covariate shocks: a novel method applied in Madagascar. World Dev 2009, 37:1222-1234.

76. Calvo C, Dercon S. Vulnerability to individual and aggregate poverty. Soc Choice Welfare 2013, 41: 721-740.

77. Chhinh N, Poch B. Climate change impacts on agriculture and vulnerability as expected poverty of Kampong Speu Province, Cambodia. Int J Environ Rural Dev 2012, 3:28-37.

78. Deressa TT, Hassan RM, Ringler C. Assessing household vulnerability to climate change: the case of farmers in the Nile Basin of Ethiopia. IFPRI Discussion Paper 2009, 28.
79. Sarris A, Karfakis P. Vulnerability to covariate and idiosyncratic shocks and safety net targeting of rural households with an application to rural Tanzania. In: ERD Conference on Social Safety Nets, the European Perspectives, Paris; 2010.

80. IPCC. Climate change 2007: impacts, adaptation and vulnerability. In: Working Group II Contribution to the Fourth Assessment Report of the IPCC. Cambridge: Cambridge University Press; 2007.

81. Engle NL. Adaptive capacity and its assessment. Glob Environ Change 2011, 21:647-656.

82. Folke C, Carpenter SR, Walker B, Scheffer M, Chapin $\mathrm{T}$, Rockström J. Resilience thinking: Integrating resilience, adaptability and transformability. Ecol Society 2010, 15:20. Available at: http://www.ecologyandsociety.org/vol15/iss4/art20. (Accessed September 18, 2012).

83. Goldstein BE, ed. Collaborative Resilience. Cambridge, MA: MIT Press; 2012.

84. Smit B, Wandel J. Adaptation, adaptive capacity and vulnerability. Glob Environ Change 2006, 16:282-292.

85. Ebi K, Kovats RS, Menne B. An approach for assessing human health vulnerability and public health interventions to adapt to climate change. Environ Health Perspect 2006, 114:1930-1934.

86. Intergovernmental Panel on Climate Change (IPCC). Climate change 2001: impacts, adaptation and vulnerability. In: McCarthy JJ, Canziani OF, Leary NA, Dokken DJ, White KS, eds. Contribution of Working Group II to the Third Assessment Report of the Intergovernmental Panel on Climate Change. Cambridge: Cambridge University Press; 2001.

87. Vayda AP, McCay BJ. New directions in ecology and ecological anthropology. Annu Rev Anthropol 1975, 4:293-306.

88. McCay BJ. Optimal foragers or political actors? Ecological analyses of a New Jersey fishery. Am Ethnol 1981, 11:356-382.

89. Sonn CC, Fisher AT. Sense of community: community resilient responses to oppression and change. J Community Psychol 1998, 26:457-472.

90. Jakobsen KT. Using a livelihood asset-based approach for measuring risk-management abilities and adaptation policy targeting. In: Paper Presented at the ICARUS II Conference, University of Michigan, 5-8 May, 2011. Available at: http://www.icarus.info/wp-content/uploads/ 2011/589-Using_a_Livelihood_Asset-based_Approach_ for_Adaptation_Policy_targeting.pdf. (Accessed January 22, 2012).

91. Nelson R, Kokic P, Crimp S, Martin P, Meinke H, Howden SM, de Voil P, Nidumolu U. The vulnerability of Australian rural communities to climate variability and change: part II - integrating impacts with adaptive capacity. Environ Sci Policy 2010, 13:18-27. 
92. Chaudhuri S, Jalan J, Suryahadi A. Assessing household vulnerability to poverty: a methodology and estimates for Indonesia. Department of Economics Discussion Paper No. 0102-52. New York: Columbia University; 2002.

93. Christiaensen L, Subbarao K. Towards an understanding of household vulnerability in rural Kenya. J Afr Econ 2005, 14:520-558.

94. Chaudhuri S. Assessing household vulnerability to poverty: concepts, empirical methods and illustrative examples. Mimeo. New York: Columbia University; 2003.

95. Suryahadi A, Sumarto S. Poverty and vulnerability in Indonesia before and after the economic crisis. Asian Econ J 2003, 17:45-64.
96. Crane TA, Roncoli C, Hoogenboom G. Adaptation to climate change and climate variability: the importance of understanding agriculture as performance. NJAS Wageningen J Life Sci 2011, 57:179-185.

97. Nyantakyi-Frimpong H, Bezner-Kerr R. The relative importance of climate change in the context of multiple stressors in semi-arid Ghana. Glob Environ Chang 2015, 32:40-56.

98. Gillard R, Gouldson A, Paavola J, Van Alstine J. Transformational responses to climate change: beyond a systems perspective of social change in mitigation and adaptation. WIREs Clim Change 2016, 7:251-265. 